\title{
Optimal Planning of Distributed Generation for Improved Voltage Stability and Loss Reduction
}

\author{
S. Kumar Injeti \\ Sr. Assistant Professor \\ Dept. of EEE, \\ Sir CRR College of Engineering \\ Eluru, A.P., India-534007
}

\author{
Dr. Navuri P Kumar \\ Associate Professor \\ Dept. of EE
}

A.U. College of Engineering, Andhra University, Vizag, India.

\begin{abstract}
The impending deregulated environment facing the electric utilities in the twenty first century is both a challenge and an opportunity for a variety of technologies and operating scenarios. Changing regulatory and economic scenarios, energy savings and environmental impacts are providing impetus to the development of an Active Distribution Networks (ADN), which is predicated to play an increasing role in the electric power system in the near future. Connecting Distributed Generator (DG) to a passive distribution network becomes an active distribution network. Distributed Generators effectively reduce the real power losses and improve the voltage profile in Radial Distribution Networks (RDN). In this paper planning and operation of active distribution networks, with respect to placement and sizing of Distributed Generators are discussed with the help of a new methodology. DG unit placement and sizing were calculated using fuzzy logic and new analytical method respectively. A detailed performance analysis was carried out on 12-bus, 33-bus and 69-bus radial distribution networks to demonstrate the effectiveness of the proposed methodology. The obtained results are presented in graphical manner.
\end{abstract}

\section{Keywords}

distributed generation, radial distribution network, sizing, placement, fuzzy, voltage stability, etc.

\section{Nomenclature}

$\begin{array}{ll}\mathrm{P}_{\mathrm{TL}} & \text { total power loss } \\ \begin{array}{l}\mathrm{P}_{\mathrm{La}} \\ \text { current }\end{array} & \text { total power loss due to active component of } \\ \mathrm{P}_{\mathrm{Lr}} & \text { total power loss due to reactive component } \\ \text { of current } & \text { active branch current } \\ \mathrm{I}_{\mathrm{a}} & \text { reactive branch current } \\ \mathrm{I}_{\mathrm{r}} & \text { resistance of the branch } \\ \mathrm{R} & \text { reactance of the branch } \\ \mathrm{X} & \text { ampere } \\ \mathrm{A} & \text { mega watt } \\ \mathrm{MW} & \end{array}$
Mvar
mega volt ampere reactive

$\begin{array}{ll}\text { Abbreviations } \\ \text { ADN } & \text { active distribution network } \\ \text { DG } & \text { distributed generator } \\ \text { RDN } & \text { radial distribution network } \\ \text { T\&D } & \text { transmission and distribution } \\ \text { G.A } & \text { genetic algorithm }\end{array}$

WODG without distributed generator

WDG with distributed generator

FIS fuzzy inference system

VSI voltage stability index

PLI power loss index

DGSI distributed generator suitability index

$\Delta \quad$ small change in variable i node

\section{INTRODUCTION}

Utilities are continuously planning the expansion of their existing electrical networks in order to face the load growth and to properly supply their consumers. Distribution system provides a final link between the high voltage transmission system and the consumer. Electricity networks are in the era of major transition from stable passive distribution networks with unidirectional electricity transportation to active distribution networks with bidirectional electricity transportation. Distribution networks without any DG units are passive since the electrical power is supplied by the national grid system to the customers embedded in the distribution networks. It becomes active when DG units are added to the distribution system leading to bidirectional power flows in the networks [1]. In an active distribution network the amount of energy lost in transmitting electricity is less as compared to the passive 
distribution network, because the electricity is generated very near the load centre, perhaps even in the same building. Active Distribution Network has several advantages like reduced line losses, voltage profile improvement, reduced emission of pollutants, increased overall efficiency, improved power quality and relieved $T \& D$ congestion. Hence, utilities and distribution companies need tools for proper planning and operation of Active Distribution Networks. The most important benefits are reduction of line losses and voltage stability improvement. They are crucially important to determine the size and location of DG unit to be placed. Studies indicate that poor selection of location and size would lead to higher losses than the losses without DG [2]. In [3], an analytical approach has been presented to identify appropriate location to place single DG in radial as well as loop systems to minimize losses. But, in this approach, optimal sizing is not considered. Loss Sensitivity Factor method (LSF) [4] is based on the principle of linearization of the original nonlinear equation (loss equation) around the initial operating point, which helps to reduce the amount of solution space. The LSF method has widely used to solve the capacitor allocation problem. Optimal placement of DG units is determined exclusively for the various distributed load profiles to minimize the total losses. They have iteratively increased the size of DG unit at all buses and then calculated the losses; based on loss calculation they ranked the nodes. Top ranked nodes are selected for DG unit placement. The Genetic Algorithm (G.A) based method to determine size and location of DG unit is used in [5]. They have addressed the problem in terms of cost, considering cost function may lead to deviation of exact size of the DG unit at suitable location. It always gives near optimal solution, but they are computationally demanding and slow in convergence. In this paper, a new analytical expression to calculate optimum size and fuzzy logic to identify the optimum location for DG placement are proposed. The DG is considered to be located in the primary distribution system and the objective of the DG placement is to reduce the losses and improve the voltage profile. The cost and other associated benefits have not been considered while solving the location and sizing problem. The sizing and placement of DG is based on single instantaneous demand at peak, where the losses maximum and voltage is minimum. The proposed methodology is suitable for allocation of single DG in a given radial distribution network.

\section{LOAD FLOW STUDY}

Conventional Newton_Raphson and Gauss_Seidel methods may become inefficient in the analysis of distribution systems, due to the special features of distribution networks, that is, radial structure, high $\mathrm{R} / \mathrm{X}$ ratio and unbalanced loads, etc. These characteristic features make the distribution systems power flow computation different and somewhat difficult to analyze as compared to the transmission systems when the conventional power flow algorithms are employed [6]. Various methods are available in the literature to carry out the analysis of balanced and unbalanced radial distribution systems [7-19]. Methods developed for the solution of ill-conditioned radial distribution systems may be divided into two categories. The first type of methods [7-9] is utilized by proper modification of existing methods such as, Newton_Raphson and Gauss_Seidel. On the other hand, the second group of methods [10-19] is based on forward and/or backward sweep processes using Kirchhoff's Laws or making use of the well-known bi-quadratic equation. Due to its low memory requirements, computational efficiency and robust convergence characteristic, forward/backward sweep based algorithms have gained the most popularity for distribution systems load flow analysis. In the present study, network topology based forward/backward sweep algorithms have been used for load flow analysis.

\section{METHODOLOGY}

A new method is introduced to minimize the losses associated with the absolute value of branch currents by optimally placing DG units. The problem of DG unit placement consists of determining the size, location and number of DG units to be installed in a distribution system such that maximum benefits are achieved while operational constraints at different loading levels are satisfied. The total power loss in a distribution system having ' $n$ ' number of branches is given by

$$
P_{T L}=\sum_{i=1}^{n} I_{i}^{2} R_{i}
$$

$I_{i}$ is the current magnitude and $R_{i}$ is the resistance. $I_{i}$ can be obtained from load flow study. The branch current has two components, active component $I_{a}$ and reactive component $I_{r}$. The total losses associated with these two components can be written as

$$
\begin{aligned}
& P_{T L}=P_{L a}+P_{L r} \\
& P_{T L}=\sum_{i=1}^{n} I_{a i}^{2} R_{i}+\sum_{i=1}^{n} I_{r i}^{2} R_{i}
\end{aligned}
$$

For a given configuration of a single source radial distribution network, the losses $\mathrm{P}_{\mathrm{La}}$ associated with the active component of branch current can not be minimized because all the active power must be supplied by the source at the root bus. This is not true if DG units are to be placed at different locations for loss reduction that is real power can be supplied locally by using DG units of optimum size to minimize $\mathrm{P}_{\mathrm{La}}$ associated with the active component of branch current. However there is significant change in reactive power loss with DG unit in distribution system.

\subsection{Identification of optimal DG Size}

Consider RDN with ' $n$ ' branches. Let a DG unit be placed at bus ' $m$ ' and ' $\beta$ ' be a set of branches connected between the source and DG unit. If the DG unit is placed at bus ' $X$ ' then ' $\beta$ ' consists of branches $X_{1}, X_{2} \ldots \ldots \ldots \ldots, X_{n}$. The DG unit supplies real component of current $I_{a}$ and for radial distribution network it changes only the active component of current of branch set ' $\beta$ '. The current of other branches is not affected by the DG unit. The new active component of current is

$$
I_{a i}^{n e w}=I_{a i}+D G_{i} I_{D G}
$$


$D G_{i}=1$ if $i \in \beta$ otherwise 0

$I_{a i}$ is the active component of current of $i^{\text {th }}$ branch in the original system obtained from the load flow solution. The $\mathrm{P}_{\mathrm{La}}{ }^{\text {com }}$ is associated with the active component of branch currents in the compensated system. For a DG unit placed at node ' $k$ ', the system losses are

$P_{L a}{ }^{c o m}=\sum_{i=1}^{k}\left(I_{a i}+D G_{i} I_{D G}\right)^{2} R_{i}+\sum_{k+1}^{n} I_{a i}^{2} R_{i}+\sum_{i=1}^{n} I_{r i}^{2} R_{i}$

\section{$I_{D G}=D G$ unit current}

Subtracting Eq. (5) from Eq. (3), loss reduction due to the introduction of DG unit at node ' $\mathrm{k}$ ' is obtained.

$$
\Delta P_{k}=-2 I_{D G} \sum_{i=1}^{n} D G_{i} I_{a i} R_{i}-I_{D G}^{2} \sum_{i=1}^{k} D G_{i} R_{i}
$$

Assuming no significant change in node voltage with DG unit power that can be generated

$P_{D G}=I_{D G} V_{k}$

The idea is to place a DG unit with a proper size and location such that the system loss reduction is maximized using Eq. (6). For system loss reduction to be maximum the DG unit must be placed at node 'k'.

$$
\frac{\partial P_{k}}{\partial I_{D G}}=0
$$

$I_{D G}=-\frac{\sum_{i=1}^{k} D G_{i} I_{a i} R_{i}}{\sum_{i=1}^{k} D G_{i} R_{i}}$

$I_{D G}=\frac{\sum_{i \in \beta} I_{a i} R_{i}}{\sum_{i \in \beta} R_{i}}$ By substuting Eq. (9) in Eq. (7)

The expression for maximum loss reduction

$$
\Delta P_{\max }=\frac{\left(\sum_{i=1}^{k} D G_{i} I_{a i} R_{i}\right)^{2}}{\sum_{i=1}^{k} D G_{i} R_{i}}
$$

It is noted that the loss reduction is always positive. This process can be repeated for all the buses to get the highest possible loss saving for a singly located DG unit.

\subsection{Identification of Optimal DG Location - Fuzzy approach}

This study presents a fuzzy approach to determine the suitable locations for DG placement. Two objectives are considered while designing a fuzzy logic for identifying the optimal DG locations. They are (i) to minimize the real power loss and (ii) to maintain voltage within permissible limits. Voltage stability and power loss indices of distribution system are modeled by fuzzy membership functions. A fuzzy inference system (FIS) containing a set of rules is then used to determine the DG placement suitability of each node in the distribution system. The DG unit can be placed on the nodes with highest suitability index. A set of fuzzy rules has been used to determine suitable locations in a distribution system. Two input and one-output variables are selected. Input variable-1 is Voltage Stability Index (VSI) and Input variable-2 is the Power Loss Index (PLI). Output variable is DG suitability index (DGSI). Five membership functions are selected for VSI. They are L, LN, N, $\mathrm{HN}$ and $\mathrm{H}$. These membership functions are trapezoidal and triangular as shown in Fig. 1. Five membership functions are selected for PLI. They are L, LM, M, HM and H. All the five membership functions are triangular as shown in Fig. 2. Five membership functions are selected for DGSI. They are L, LM, $\mathrm{M}, \mathrm{HM}$ and $\mathrm{H}$. These functions are also triangular as shown in Fig. 3. For the DG allocation problem, rules are defined to determine the suitability of a node for DG installation. Such rules are expressed in the following manner: IF premise (antecedent), THEN conclusion (consequent). For determining the suitability of DG placement at a particular node, a set of multiple antecedent fuzzy rules have been established. The inputs to the rules are the voltage and Loss indices and the output is the suitability of DG placement. FIS editor receives inputs from the load flow program. Several rules may fire with some degree of memberships. FIS is based on Mamdani maxmin and max-prod implication methods of inference. These methods determine the aggregated output from the set of triggered rules. The max-min method involves truncating the consequent membership function of each fired rule at the minimum membership value of all the antecedents. A final aggregated membership function is achieved by taking the union of all truncated consequent membership functions of the fired rules. After calculating the suitability membership function, it is 
to be de-fuzzified using the centroid method in order to determine the optimal DG location [20].

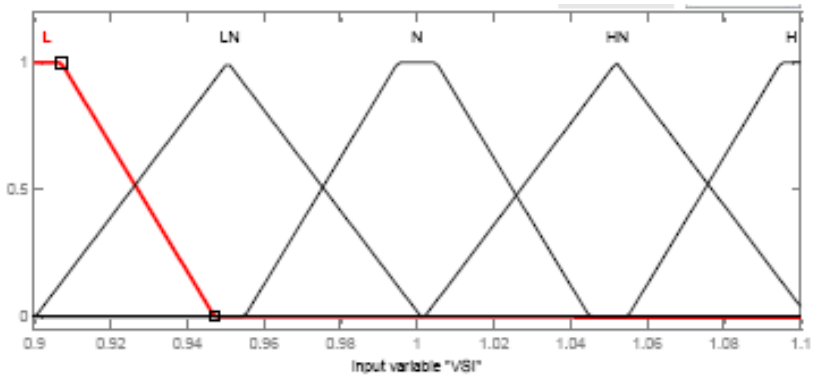

Fig 1: Membership function plot for VSI

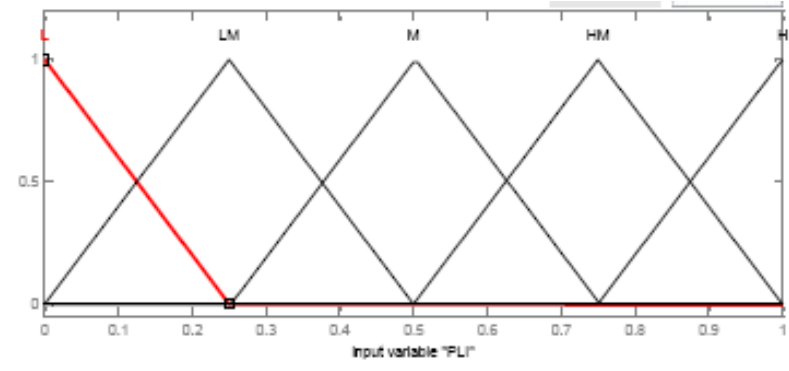

Fig 2: Membership function plot for PLI

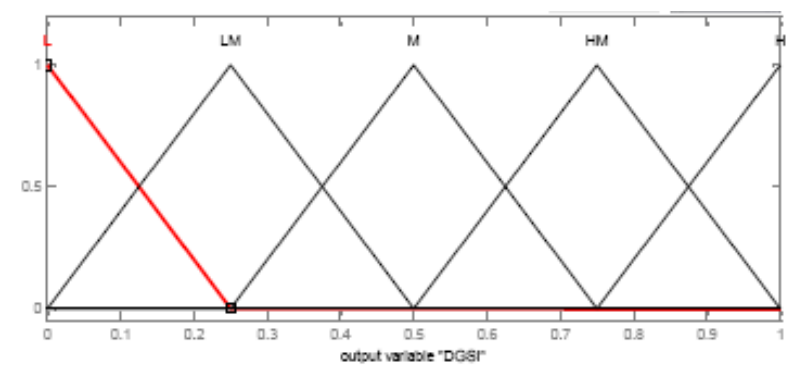

Fig 3: Membership function plot for DGSI

\section{STEPS FOLLOWED IN ALGORITHM}

There are many computational steps involved in finding the optimal DG size and location to minimize losses in a radial distribution system are:

1. Run the load flow program. Select the bus where the maximum loss and low voltage is using fuzzy logic tool box. Corresponding DG size is calculated using Eq's, respectively.

2. Repeat this for all the buses except the source bus. Identify the bus using the fuzzy logic that provides highest loss saving.

3. Compensate the bus with the highest loss with the corresponding DG unit found from Eq. (7).

4. Repeat the steps 1) and 2) to get the next DG size and hence sequence of buses to be compensated.
5. Once the sequence of buses is known determine the optimum DG unit sizes and the corresponding loss saving.

Since the system load is time variant and load duration curve of the system can be approximated .It is assumed that load level is constant. The above algorithm provides the optimal DG sizes and locations for a given load level.

\section{RESULTS}

The proposed method is tested on three different test systems with different sizes, to show that it can be implemented in distribution systems of various configurations and sizes. The parameters of the first test system are given in Appendix. The second test system is 33-bus system [21], the total real power and reactive power loads on this system are $3.72 \mathrm{MW}$ and 2.3 Mvar. The initial real and reactive power losses in the system are 0.211 MW and 0.143 Mvar. The third system is a 69-bus system [22], the total real power and reactive power loads on this system are 3.80 MW and 2.69 Mvar. The initial real and reactive power losses in the system are $0.225 \mathrm{MW}$ and 0.102 Mvar. Based on the method described previously, the optimal sizes of DG are calculated at all buses for the three test systems. Fig. 4, Fig. 5 and Fig. 6 show the optimal sizes of Dg unit at all buses for 12,33 and 69 bus distribution test systems, respectively. With the help of FIS editor optimal location of Dg unit is found where real power loss is more and voltage is low. The optimal locations of DG unit are bus9, bus 6 and bus 61 for 12,33 and 69 bus distribution test systems where total power losses attain the minimum value.

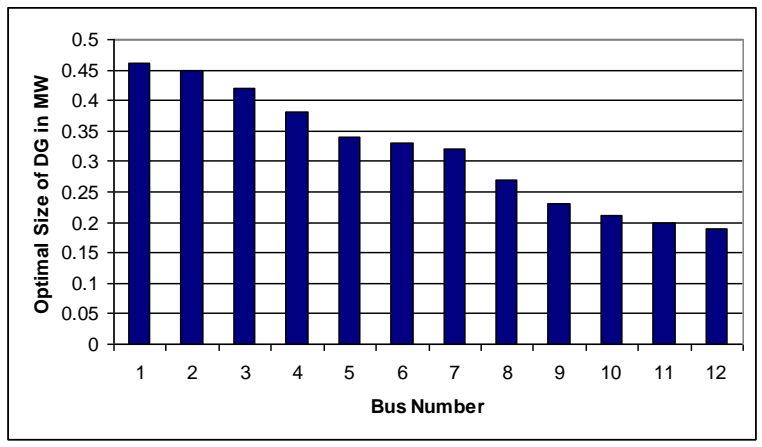

Fig 4: Optimal DG unit sizes for 12-bus radial distribution system

The real and reactive power losses for the corresponding optimal DG unit sizes are shown in Fig. 7, Fig. 8, Fig. 9, Fig. 10, Fig. 11 and Fig. 12. Improvement in voltage stability was observed from Fig. 13, Fig. 14, and Fig. 15 for 12, 33 and 69 bus distribution test systems, respectively. Results obtained are tabulated in Table 1. In Table 2, for three different test system, the results of proposed method, total power losses with and without DG are tabulated. It is seen that the total power losses are significantly reduced for all test systems. 


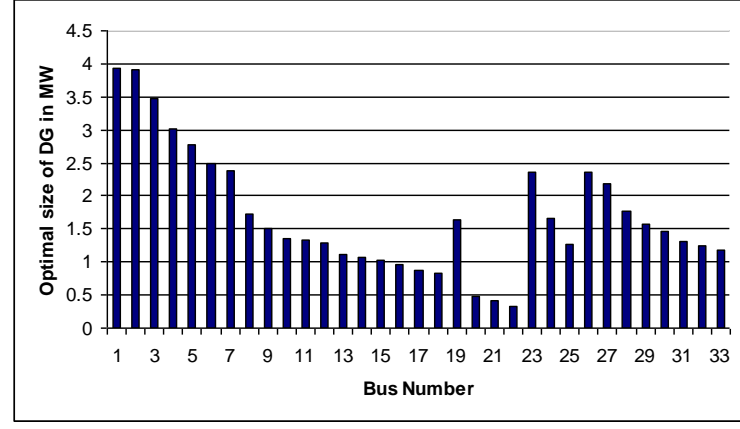

Fig 5: Optimal DG unit sizes for 33-bus radial distribution system

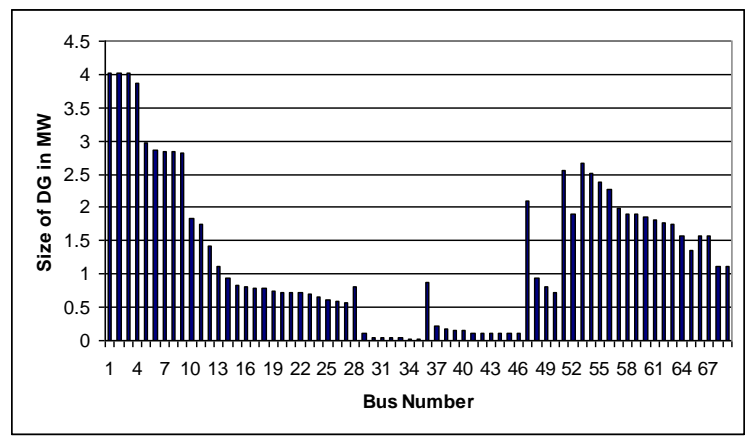

Fig 6: Optimal DG unit sizes for 69-bus radial distribution system

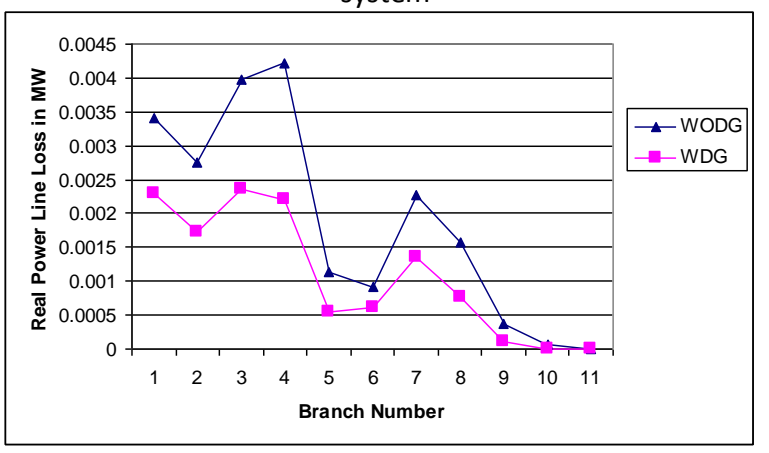

Fig 7: Real power line losses of 12-bus radial distribution system with and without DG

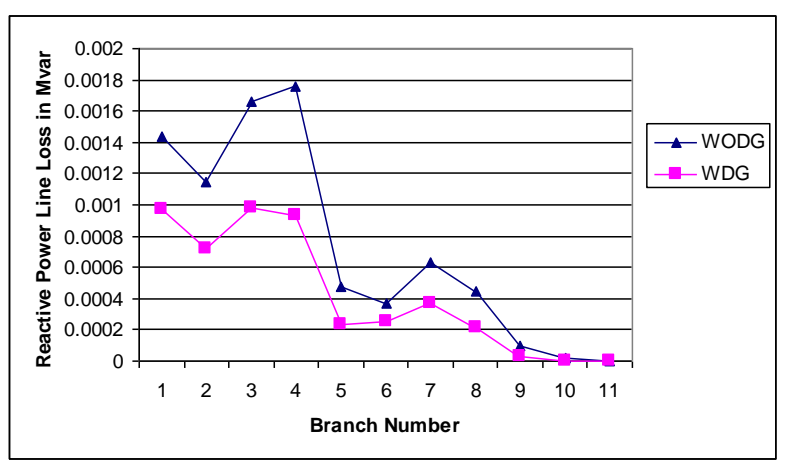

Fig 8: Reactive power line losses of 12-bus radial distribution system with and without DG

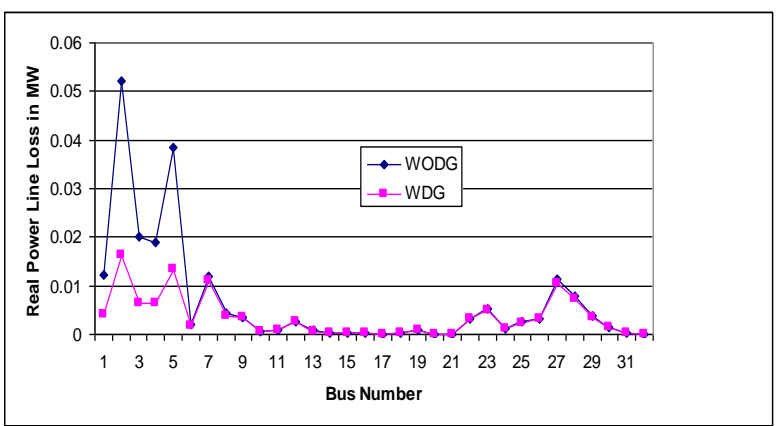

Fig 9: Real power line losses of 33-bus radial distribution system with and without DG

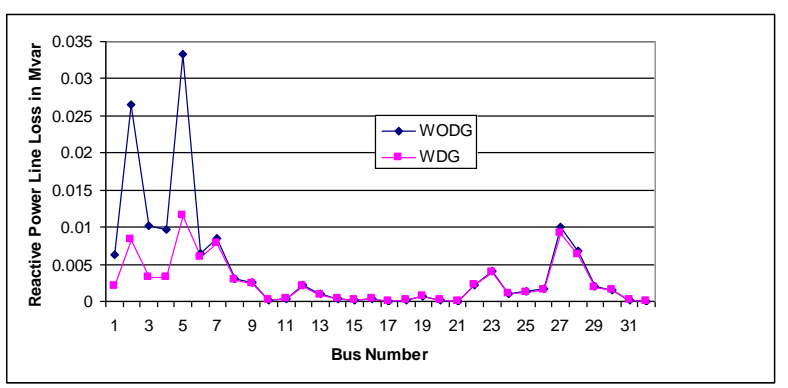

Fig 10: Reactive power line losses of 33-bus radial distribution system with and without DG

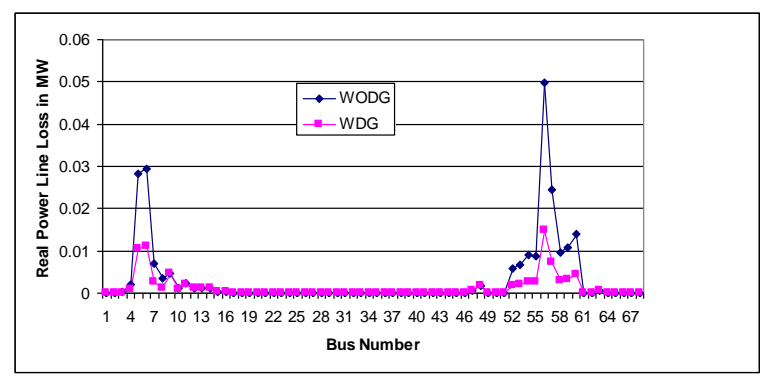

Fig 11: Real power line losses of 69-bus radial distribution system with and without DG

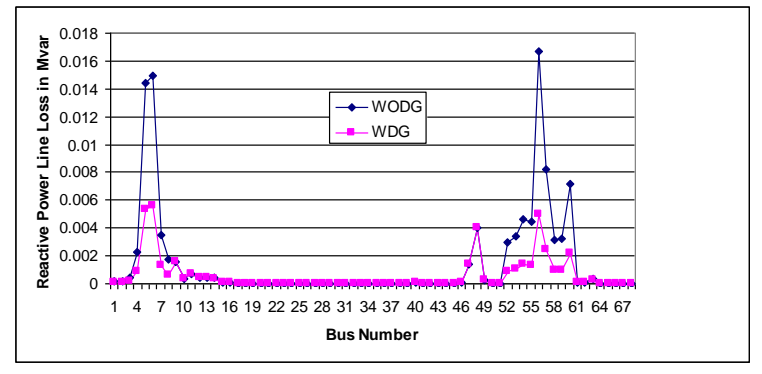

Fig 12: Reactive power line losses of 69-bus radial distribution system with and without DG 


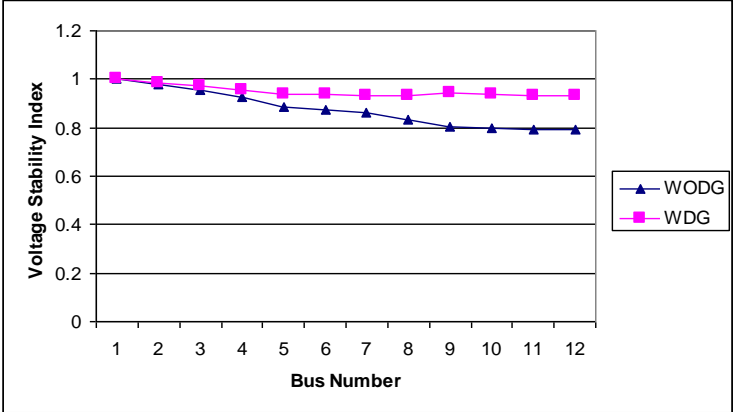

Fig 13: Voltage stability index of 12-bus radial distribution system with and without DG

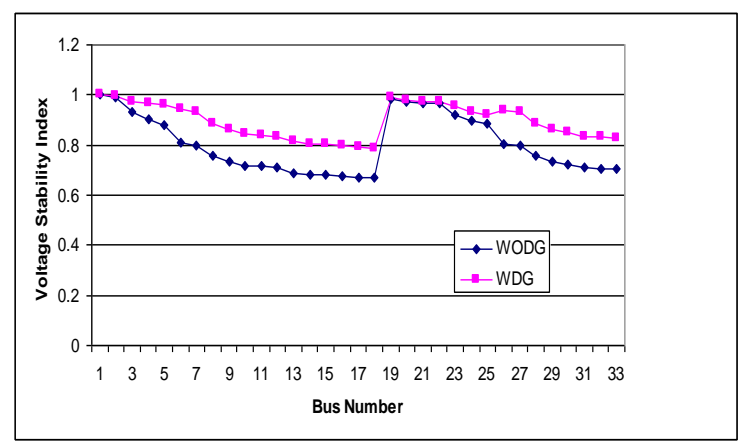

Fig 14: Voltage stability index of 33-bus radial distribution system with and without DG

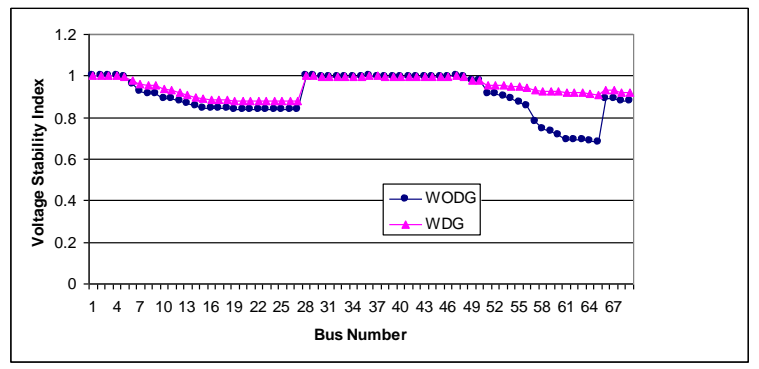

Fig 15: Voltage stability index of 69-bus radial distribution system with and without DG

Table 1 Results of critical bus analysis and comparison of active branch currents with and without DG for test systems

\begin{tabular}{|c|c|c|c|c|c|}
\hline \multirow{2}{*}{$\begin{array}{l}\text { Ty } \\
\text { pe }\end{array}$} & \multirow{2}{*}{$\begin{array}{c}\text { Bus } \\
\text { no. } \\
\text { corres } \\
\text { pondi } \\
\text { ng to } \\
\text { lowest } \\
\text { voltag } \\
\text { e }\end{array}$} & \multicolumn{2}{|c|}{$\begin{array}{l}\text { Voltage in p.u. } \\
\text { / VSI }\end{array}$} & \multicolumn{2}{|c|}{$\begin{array}{l}\text { Active branch } \\
\text { current in } \\
\text { branch1 in (A) }\end{array}$} \\
\hline & & $\begin{array}{l}\text { W.O. } \\
\text { D.G }\end{array}$ & $\begin{array}{c}\text { W.D. } \\
\text { G }\end{array}$ & $\begin{array}{l}\text { W.O. } \\
\text { D.G }\end{array}$ & W.D.G \\
\hline $\begin{array}{l}12- \\
\text { bus }\end{array}$ & 12 & $\begin{array}{c}0.9433 \\
/ 0.792 \\
0\end{array}$ & $\begin{array}{c}0.982 \\
3 / 0.93 \\
11\end{array}$ & 41.42 & 15.76 \\
\hline
\end{tabular}

\begin{tabular}{|c|c|c|c|c|c|}
\hline $\begin{array}{l}33- \\
\text { bus }\end{array}$ & 18 & $\begin{array}{c}0.9037 \\
/ 0.667 \\
2\end{array}$ & $\begin{array}{c}0.942 \\
3 / 0.78 \\
86\end{array}$ & 310.11 & 157.25 \\
\hline $\begin{array}{l}69- \\
\text { bus }\end{array}$ & 61 & $\begin{array}{c}0.9091 \\
/ 0.683 \\
3\end{array}$ & $\begin{array}{c}0.981 \\
7 / 0.92 \\
88\end{array}$ & 318.09 & 159.18 \\
\hline
\end{tabular}

Table-2 Results of proposed method for test systems

\begin{tabular}{|c|c|c|c|}
\hline System Type & 12-bus & 33-bus & 69-bus \\
\hline $\begin{array}{l}\text { Optimal } \\
\text { location of } \\
\text { DG }\end{array}$ & 9-bus & 6-bus & 61-bus \\
\hline $\begin{array}{l}\text { Optimal DG } \\
\text { size in MW }\end{array}$ & 0.22 & 2.59 & 1.87 \\
\hline $\begin{array}{l}\text { Total real } \\
\text { power loss in } \\
\text { MW (WODG) }\end{array}$ & 0.02069 & 0.2110 & 0.2250 \\
\hline $\begin{array}{l}\text { Total reactive } \\
\text { power loss in } \\
\text { MVar } \\
\text { (WODG) }\end{array}$ & 0.00806 & 0.1430 & 0.1021 \\
\hline $\begin{array}{l}\text { Total real } \\
\text { power loss in } \\
\text { MW (WDG) }\end{array}$ & 0.01077 & 0.1110 & 0.0832 \\
\hline $\begin{array}{l}\text { Total reactive } \\
\text { power loss in } \\
\text { MVar (WDG) }\end{array}$ & 0.00415 & 0.0816 & 0.0405 \\
\hline $\begin{array}{l}\text { Real power } \\
\text { loss reduction } \\
\text { in } \%\end{array}$ & 52.2 & 52.6 & 57.1 \\
\hline $\begin{array}{l}\text { Reactive } \\
\text { power loss } \\
\text { reduction in } \\
\%\end{array}$ & 38.5 & 36.9 & 39.4 \\
\hline
\end{tabular}

\section{CONCLUSIONS}

The size and location of DG unit are crucial factors in the planning and operation of active distribution networks. This study presents a new methodology which can be used to determine the optimal size and placement of DG. This method is easy to be implemented and faster for the given accuracy. It is proved that the proposed method can save huge amount of 
power and achieve significant improvement in voltage stability. Installation of DG unit at one location at a time is proved to be a valid assumption in the present study. However, this paper does not consider the other benefits of DG as well as economics of it.

\section{REFERENCES}

[1] Chowdhury S, Chowdhury SP, Crossley P.2009. Micro grids and Active Distribution Networks. 1st ed. London. IET Renewable Energy Series.

[2] Willis H. L, 2000. Analytical methods and rules of thumb for modeling DG distribution interaction. IEEE Proc. PES summer meeting, vol.3, pp. 1643-1644.

[3] Wang C, and Nehrir MH. 2004. Analytical approach for optimal placement of distributed generation sources in power systems. IEEE Trans. PWRS, 19(4), pp. 2068-2076.

[4] Griffin T, Tomosovic K, Secrest D, and Law A. 2000 Placement of Dispersed Generation systems for reduced losses. In proceedings of 33rd Annual Hawaii International conference on systems sciences, Maui, Hawaii , pp. 1-9.

[5] Mardanesh M, and Gharehpattan GB. 2004. Siting and sizing of DG units using GA and OPF based technique. IEEE Region 10 Conference, 3: 331-34.

[6] Tripathy SC, Prasad GD, Malik OP, and Hope GS. 1982. Load flow solutions for Ill-conditioned power systems by a Newton-like method, IEEE Trans Power Ap Syst PAS-101 pp.3648-3657, D.O.I: 10.1049/ip-c: 19800043.

[7] Tinney WG and Hart CE. 1967. Power flow solutions by Newton's method. IEEE Trans Power Ap Syst PAS-86; 1449-1457.

[8] Zhang F and Cheng CS. 1997.A modified Newton method for radial distribution system power flow analysis. IEEE Trans Power Syst $12 ; 389-397$.

[9] Teng JH. 2002. A modified Gauss-Seidel algorithm of three-phase power flow analysis in distribution networks. Electric Power and Energy Systems 24; 97-102.

[10] Shirmohammadi D, Hong HW, Semlyen A and Luo GX. 1988. A compensation-based power flow method for weakly meshed distribution and transmission networks. IEEE Trans Power Syst 3, 753-762.
[11] Thukaram D, Banda HMW and Jerome J. 1999. A Robust three-phase power flow algorithm for radial distribution systems. Electric Power System Research 50, 227-236.

[12] Ranjan R, Venkatesh B, Chaturvedi A and Das D. 2004. Power flow solution of three-phase unbalanced radial distribution network. Electric Power Component Systems 32; 421-433.

[13] Teng JH. 2003. A direct approach for distribution system load flow solutions. IEEE Trans Power Deliver 18; 882887.

[14] Kersting WH. 2002. Distribution system modeling and analysis, CRC Press, Boca Raton, FL.

[15] Cespedes R G. 1990. New method for the analysis of distribution networks. IEEE Trans Power Deliver 5; 391 396.

[16] Haque MH. 1996. Load flow solution of distribution systems with voltage dependent load models. Electric Power System Research 36; 151-156.

[17] Eminoglu U and Hocaoglu MH. 2005. A new power flow method for radial distribution systems including voltage dependent load models. Electric Power System Research; 106-114.

[18] Luo GX and Semlyen A. 1990. An Efficient load flow for large weakly meshed networks. IEEE Trans Power Syst, 1309_1316.

[19] Rajicic D, Ackovski R and Taleski R. 1994. Voltage correction power flow. IEEE Trans Power Delivery 9; 1056-1062.

[20] Fuzzy Logic Toolbox - MATLAB User's Guide, Math works Inc.

[21] Kashem MA, Ganapathy V, Jasmon GB and Buhari M, 2000. A novel method for loss minimization in distribution networks. Proc. Int. Con. Electr. Util. Deregulation Restruct. Power Technol, April, 251-256.

[22] Baran ME and Wu FF. 1989 Optimal sizing of capacitor placement on radial distribution system. IEEE Transactions on Power Delivery; 4: 735-43. 